\title{
Simulation of a Low Cost Single Phase to Three Phase Converter using Arduino
}

\author{
Anirban Giri, Tomas Deb Adhikary, Debadyuti Banerjee
}

\begin{abstract}
This paper proposes a single phase to three phase conversion system composed of a rectifier, capacitive filter, Arduino controller, resistive switching network, buffer circuit and amplifier circuit. The proposed topology permits to operate at different frequencies by changing the coding of Arduino pulse generator. Although the effectiveness of previous work is acknowledged, none have assessed the multilevel wave generation using arduino and resistive switching network. It reduces the cost by using resistive switching technique and better accuracy as the input pulse is divided into 20 steps and finally a stepped sine wave is obtained. This converter can be easily used for motors up-to 5HP. Analysis and simulated results are presented to validate these features.
\end{abstract}

Keywords : Amplifier, signal generator, buffer circuit arrangement, rectifier.

\section{INTRODUCTION}

In some rural areas due to low density of consumers only single phase supply has been provided[5]. To overcome this problem,single phase to three phase converter can be used. Three phase motors are preferred more then the single phase motor in industrial and commercial application due to better performance[4] of efficiency,torque,ripple and power factor.[11]If a single phase induction motor is compared to a three phase induction motor, three phase induction motor is less costly[6],simple in construction and small in size[13]. The main advantage of three phase induction motor is that it takes 3 to 5 times of running current at the time of starting whereas a single phase induction motor takes 6 to 8 times of running current at the time of starting[13]. The system is based on Single phase to three phase DC link converter[10].Previously the Single phase to three phase conversion system was done by connecting passive elements and reactors with autotransformer converter.[8]This system is applicable for water pump,small rural industries,railways and some remote areas to run three phase induction motor from single phase grid.[9][12]. In most of the cases single phase power is converted to three phase power by various ways of switching process by solid state devices[2][3][10]. Mainly the switching[1] is done by PWM concept. This paper proposes a

Revised Manuscript Received on July 22, 2019.

Anirban Giri, Department of Electrical Engineering, M I E T, Bandel, India.

Tomas Deb Adhikary, Department of Electrical Engineering, M I E T, Bandel, India.

Debadyuti Banerjee, Department of Electrical Engineering, M I E T, Bandel, India. stepped wave based conversion system. This process is suitable for high power application and it reduces the output voltage harmonics[7].The converter is totally controlled by Arduino. For simplicity in the process stepped sine wave is generated by the help of Arduino and resistive network, and this is filtered. This converter is able to supply a constant frequency \& well balanced three phase power.

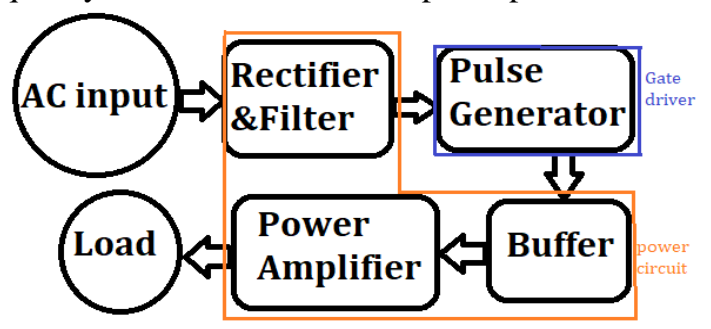

Fig. 1.Block diagram of the system

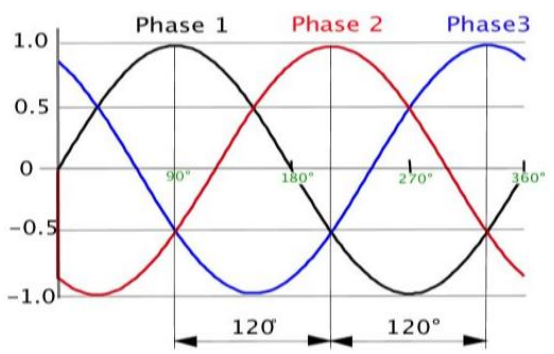

Fig. 2. Three phase sine wave

In a three phase system all the phase must be in same frequency. The signal of a phase will repeat after $120^{\circ}$ in next phase.

Time period $(\mathrm{T})=1 /$ frequency $(\mathrm{f})$

Full cycle of a signal is 360

Phase difference is $(\mathrm{T} \times 120) / 360=\mathrm{T} / 3$

A complete cycle is divided into 20 steps.

Time period of each pulse $=(\mathrm{T} / 3) / 20=20 \mathrm{~T} / 3$

\section{DESIGN OF STEPPED SINE WAVE INVERTER}

A sine wave can be build up by adding square waves of various DC voltages in a particular way. This process offers a harmonics reduction topology. This waves basically generates by continuous switching of different $\mathrm{dc}$ voltages at a particular manner.By using proper design the harmonics of the system can be reduced. 
For better accuracy in the output signal the signal is divided in 20 steps.A microcontroller always generate constant voltage pulse.By designing a proper biased resistive network that particular voltage pulse is converted to a particular voltage. Basically it works like a switching process.From the resistive network the different output voltage are generating continuously.So the output Voltage is a sine wave.

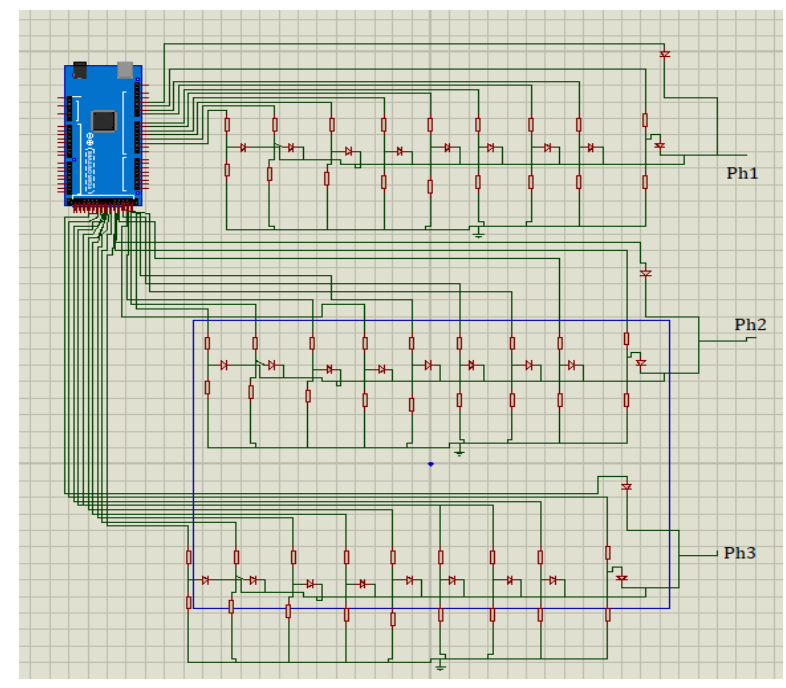

Fig. 3. Three phase stepped sine wave generator

Table- I: Timing logic of phase 1

\begin{tabular}{|l|c|c|c|c|c|c|c|c|c|c|}
\hline interval & $\mathrm{g}$ & $\mathrm{a}$ & $\mathrm{b}$ & $\mathrm{c}$ & $\mathrm{d}$ & $\mathrm{e}$ & $\mathrm{f}$ & $\mathrm{g}$ & $\mathrm{h}$ & $\mathrm{i}$ \\
\hline $0-18$ & 1 & 0 & 0 & 0 & 0 & 0 & 0 & 0 & 0 & 0 \\
\hline $18-36$ & 0 & 1 & 0 & 0 & 0 & 0 & 0 & 0 & 0 & 0 \\
\hline $36-54$ & 0 & 0 & 1 & 0 & 0 & 0 & 0 & 0 & 0 & 0 \\
\hline $54-72$ & 0 & 0 & 0 & 1 & 0 & 0 & 0 & 0 & 0 & 0 \\
\hline $72-90$ & 0 & 0 & 0 & 0 & 1 & 0 & 0 & 0 & 0 & 0 \\
\hline $90-108$ & 0 & 0 & 0 & 0 & 0 & 1 & 0 & 0 & 0 & 0 \\
\hline $\begin{array}{l}108-12 \\
6\end{array}$ & 0 & 0 & 0 & 0 & 1 & 0 & 0 & 0 & 0 & 0 \\
\hline $\begin{array}{l}126-14 \\
4\end{array}$ & 0 & 0 & 0 & 1 & 0 & 0 & 0 & 0 & 0 & 0 \\
\hline $\begin{array}{l}144-16 \\
2\end{array}$ & 0 & 0 & 1 & 0 & 0 & 0 & 0 & 0 & 0 & 0 \\
\hline $\begin{array}{l}162-18 \\
0\end{array}$ & 0 & 1 & 0 & 0 & 0 & 0 & 0 & 0 & 0 & 0 \\
\hline $\begin{array}{l}180-19 \\
8\end{array}$ & 1 & 0 & 0 & 0 & 0 & 0 & 0 & 0 & 0 & 0 \\
\hline $\begin{array}{l}198-21 \\
6\end{array}$ & 0 & 0 & 0 & 0 & 0 & 0 & 1 & 0 & 0 & 0 \\
\hline $\begin{array}{l}216-23 \\
4\end{array}$ & 0 & 0 & 0 & 0 & 0 & 0 & 0 & 1 & 0 & 0 \\
\hline $\begin{array}{l}234-25 \\
2\end{array}$ & 0 & 0 & 0 & 0 & 0 & 0 & 0 & 0 & 1 & 0 \\
\hline $\begin{array}{l}252-27 \\
0\end{array}$ & 0 & 0 & 0 & 0 & 0 & 0 & 0 & 0 & 0 & 1 \\
\hline $\begin{array}{l}270-28 \\
8\end{array}$ & 0 & 0 & 0 & 0 & 0 & 0 & 0 & 0 & 0 & 0 \\
\hline $\begin{array}{l}288-30 \\
6\end{array}$ & 0 & 0 & 0 & 0 & 0 & 0 & 0 & 0 & 0 & 1 \\
\hline $\begin{array}{l}306-32 \\
4\end{array}$ & 0 & 0 & 0 & 0 & 0 & 0 & 0 & 0 & 1 & 0 \\
\hline $\begin{array}{l}324-34 \\
2\end{array}$ & 0 & 0 & 0 & 0 & 0 & 0 & 0 & 1 & 0 & 0 \\
\hline $\begin{array}{l}342-36 \\
0\end{array}$ & 0 & 0 & 0 & 0 & 0 & 0 & 1 & 0 & 0 & 0 \\
\hline
\end{tabular}

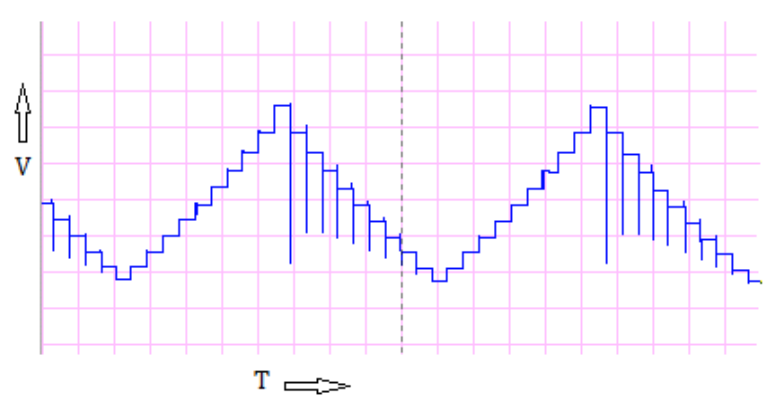

Fig. 4. Output of phase 1

\section{BUFFER \& AMPLIFICATION}

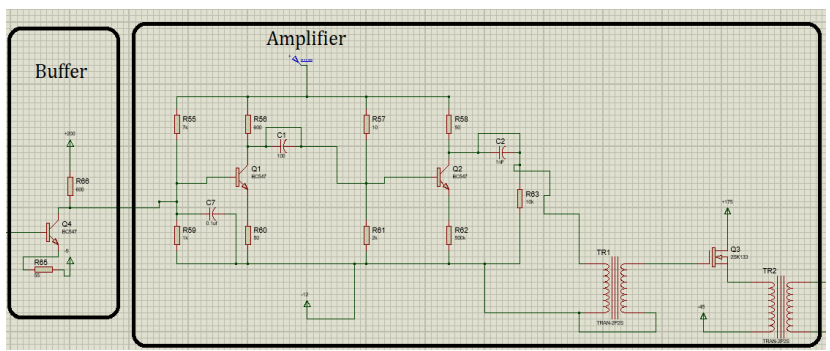

Fig. 5.Buffer\&amplification circuit

The buffer circuit is mainly used to isolate the signal generator circuit to the amplification circuit.This proposed circuit has less distortion.

In amplification part, a two stage amplifier is used to amplify the signal.This amplified voltage is not too much.To reduce the amplifier cost a low power rating transformer is used to boost up the voltage .Main power amplifier is the MOSFET amplifier.So it takes very less current from the transformer.In MOSFET amplifier a power transformer is used to isolate the system from the load and increase the output voltage level.

\section{RESULT AND DISCUSSION}

The proposed system has been implemented by simulation in software named "Proteus 8 Professional". We have simulate this circuit in "Proteus 8 Professional" because it offers real time based simulation. The experimental data has been shown bellow.To reduce the ripple the rectified voltage is filtered by a simple capacitor type filter.The "Arduino mega" works as pulse generator.Its output pulse is always $5 \mathrm{~V}$,by using proper biased resistive network. The continuously generated pulse is converted to a stepped sine wave.The output power of the stepped sine wave is in miliwatt range.To boost up the power, amplifier circuit is needed.A proper biased buffer circuit is used to isolate the signal generating part from the amplification part.A small 2 stage amplifier is used to boost up the power.We can consider the output signal as control signal.A low power rating transformer is used to step up the control signal.Now the signal is fed to MOSFET amplifier.

Published By:

Blue Eyes Intelligence Engineering 
Due to the high input impedance of the MOSET, it takes very low power as input.The MOSFET amplifier is fed from main DC supply.Power transformer is used to increase the voltage level of the MOSFET amplifier and isolate the amplifier part from the load circuit. Output voltage and current are measured by voltmeter and ammeter respectively.The output waveform is observed by the digital oscilloscope in Proteus.The output performance is taken for different value of load.The simulation results are given below.By observing the simulations results, it is clear that the system is well balanced and frequency does not depend on load.This system can be used for up-to 5HP load.

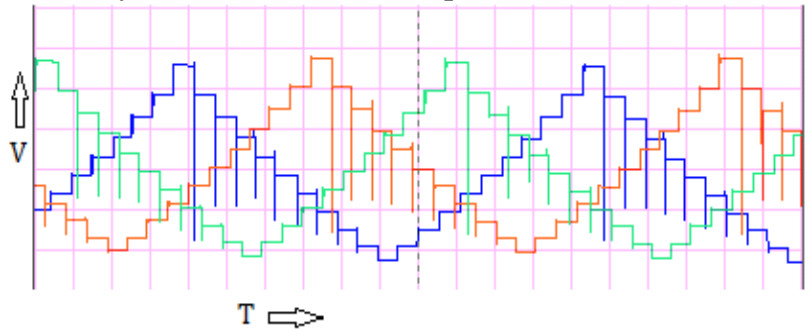

Fig. 6. Output waveform at three phase stepped sine wave generator

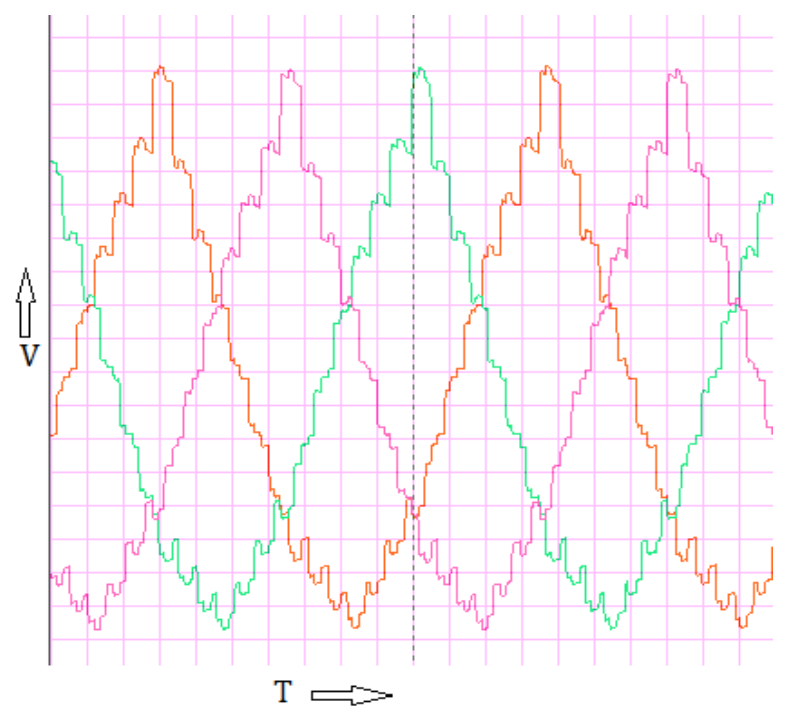

Fig. 7. Output three phase waveform at no load

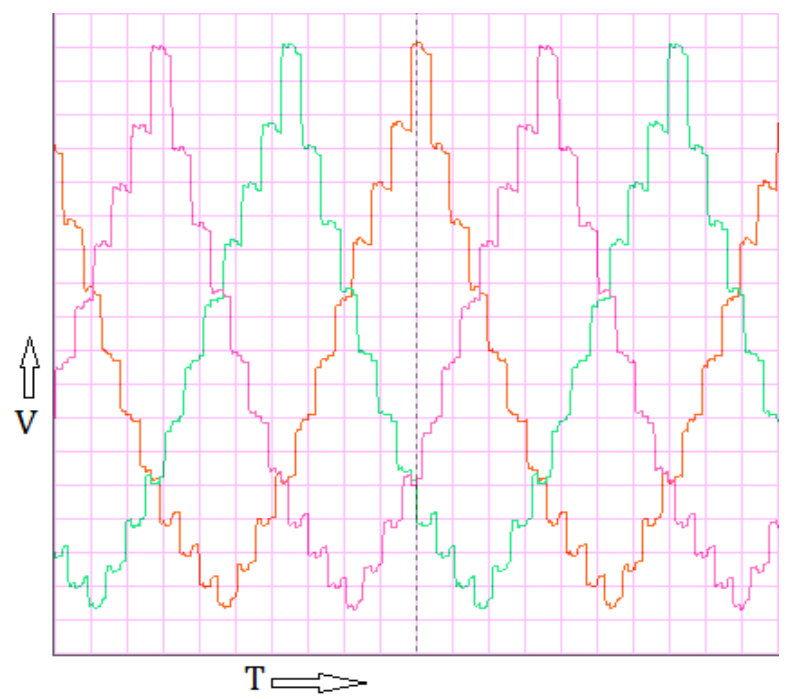

Fig. 8. Output waveform of three phase at load terminal at $100 /$ ph in star

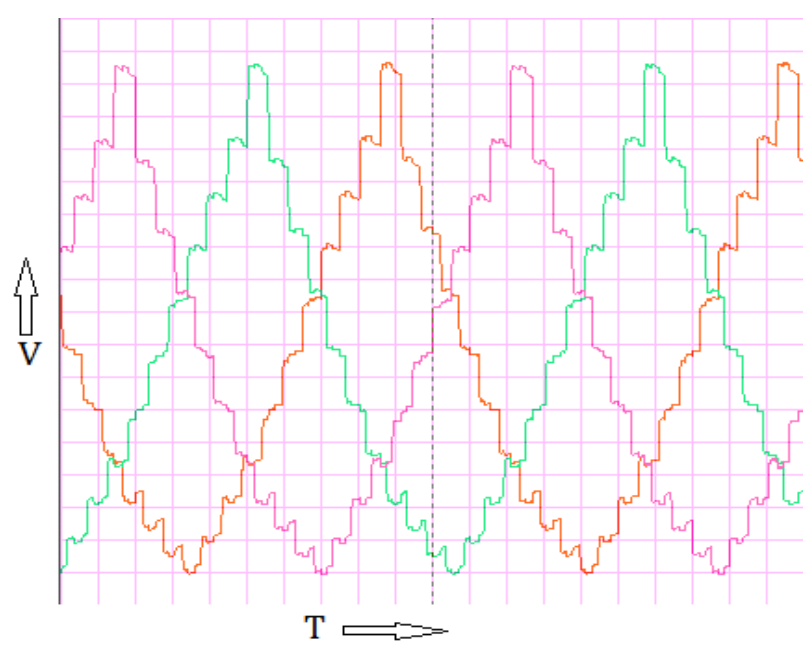

Fig. 9. Output waveform at load at $25 \mathrm{ohm} / \mathrm{ph}$ in star

Table- II: Output characteristic table

\begin{tabular}{|l|l|l|l|l|l|l|}
\hline $\begin{array}{l}\text { LOAD In star } \\
\text { connection/ph }\end{array}$ & \multicolumn{4}{|l|}{$\begin{array}{l}\text { Line Voltage } \\
\text { (Volts) }\end{array}$} & \multicolumn{4}{l|}{$\begin{array}{l}\text { Line current } \\
\text { (Amp) }\end{array}$} \\
\hline & V1 & V2 & V3 & I1 & I2 & I3 \\
\hline No load & 433 & 435 & 427 & 0.00 & 0.00 & 0.00 \\
\hline $100 \mathrm{ohm}$ & 423 & 419 & 422 & 2.49 & 2.44 & 2.45 \\
\hline $50 \mathrm{ohm}$ & 408 & 417 & 411 & 4.77 & 4.78 & 4.88 \\
\hline $75 \mathrm{ohm}$ & 421 & 421 & 411 & 3.23 & 3.30 & 3.23 \\
\hline $25 \mathrm{ohm}$ & 390 & 399 & 392 & 9.11 & 9.16 & 9.32 \\
\hline
\end{tabular}

\section{CONCLUSION}

A single phase to three phase stepped sine wave converter has been implemented using rectifier, stepped sine wave generator, buffer and amplifier circuit. The proposed topology gives output with lower distortion and better accuracy. The distortion of the stepped wave can be further eliminated by using controllers which have better accuracy then Arduino. By increasing the power rating of the amplifiers the system can be used for heavier loads.

\section{REFERENCES}

1. J. A. A. Dias, E. C. dos Santos Jr., C. B. Jacobina, M. B. R. Corrêa "Soft-Starting Techniques for Low Cost Singlephase to Three-phase Drive System Configuration" IEEE Power Electronics Specialists Conference 2008, pp. 3996-4002.

2. C. B. Jacobina, E. C. dos Santos Jr., N. Rocha, E. L. L. Fabr'icio"Single-Phase to Three-phase Drive System Using Two Parallel Single-Phase Rectibers"IEEE Power Electronics Specialists Conference 2008, pp.901-904.

3. C. B. Jacobina, E. C. dos Santos Jr., N. Rocha, E. L. L. Fabr'icio"Single-Phase to Three-phase Five-leg Converter Based on Two Parallel Single-Phase Rectifiers"35th Annual conference of IEEE Industrial Electronics, 2009, pp. 850-855.

4. Jianmin Xiao, Wei Zhang, Hideki Omori2, Keizo Matsui- "A Novel Operation Strategy for Single-to ThreePhase Matrix Converter".International Conference on Electrical Machines and System, 2009, pp. 1-6. 
5. José A. A. Dias1,2, Euzeli C. dos Santos Jr.2, Cursino B. Jacobina2, Edison R. C. da Silva2-“APPLICATION OF SINGLE-PHASE TO THREE-PHASE CONVERTER MOTOR DRIVE SYSTEMS WITH IGBT DUAL MODULE LOSSES REDUCTION".2009 Brazilian Power Electronic Conference, pp. 1155-1162.

6. Cursino Brandão Jacobina, Nady Rocha "Single-Phase to Three-Phase DC-Link Converters With Reduced Controlled Switch Count" IEEE Trans. Ind. Appl., Vol. 50, No.2, March/April 2014, pp. 1150-1160.

7. J.Nandhagopal, V.Vignesh, J. Prasanth,R. Prasanth,A. Ramkumar "Three Phase Cascaded H-Bridge Multilevel Inverter with Ac Source" IJSER, Volume 5, Issue 4, April-2014,pp.69-73.

8. Arvind K.Yadav, Nayan Wadgure, Pavan kamdi- "Conversion of single phase to three phase supply".International Journal of Research in Advent Technology (E-ISSN: 2321-9637) Special Issue 1st "ICATEST 2015”, 08 March 2015, pp.397-400.

9. Anil K Adapa, Vinod John-"Single Phase to Three Phase Power Conversion Using Reduced Rated Inverters" IEEE International Conference on the SPICES,April 2015, pp.1-6.

10. Yuvraj U. Rathod1, Mrs. M. R. Bachawad2 "Single Phase to Three Phase System Using Dual Boost Converter to Drive Induction Motor Along With Active Power Factor Correction Technique".JJAERD Volume 3, Issue 10, October -2016 pp.116-127.

11. Pooja Sahastrabuddhe, Dr.Hari Kumar Naidu "Three Level PWM Single PHSE to Three Phase Inverter using Microcontroller and Diode Clamped.” IJSTE,Volume 3, Issue 01, July 2016,pp. 220-225.

12. S. Bronshtein, B. Epshtein,A. Bronshtein "Single to Three Phase Conversion for Rural Power Applications". IEEE International Conference on the Science of Electrical Engineering,2016,pp.1-4.

13. Nima Farrokhzad Ershad, Ramin Tafazzoli Mehrjardi-“A low cost single-phase to three-phase power converter for low-power motor drive applications". IEEE Texas Power and Energy Conference,2018, pp. 1-6.

\section{AUTHORS PROFILE}

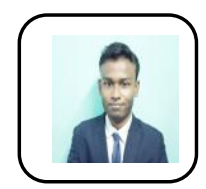

Anirban Giri pursuing B.Tech in Electrical Engineering from MODERN INSTITUTE OF ENGINEERING \& TECHNOLOGY under MAKAUT. He has participated in National Science Day exhibition at MAKAUT main campus. He has attended a international conference (ICEECC 2019) at PCMT, Kolkata. His research interests include Electrical machines, Power electronics and power system protection.

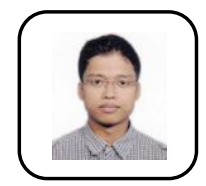

Tomas Deb Adhikary received B.Tech in Electrical Engineering from Calcutta Institute of Engineering and Management under MAKAUT and M.Tech in Mechatronics Engineering from National Institute of Technical Teachers' Training and Research under MAKAUT (Bronze Medalist). He is working as Assistant Professor in Department of Electrical Engineering, at MODERN INSTITUTE OF ENGINEERING \& TECHNOLOGY. His research interest includes filter design, sensors, electrical drives and recent advancement in transmission and distribution system.

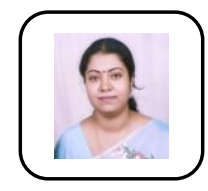

Debadyuti Banerjee received B.E in Electrical Engineering from NIT Durgapur and M.E from Jadavpur University (Gold Medalist in Illumination Engineering). She is working as HOD in Department of Electrical Engineering, at MODERN INSTITUTE OF ENGINEERING \& TECHNOLOGY. Her research interest includes power electronics applications to renewable energy, LED drivers and recent advancements in illumination engineering. 